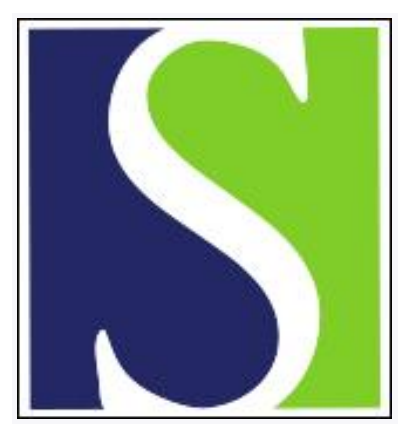

Scand J Work Environ Health 1999;25(5):410-414

https://doi.org/10.5271/sjweh.453

Issue date: Oct 1999

Retrospective versus original information on physical and psychosocial exposure at work

by Köster M, Alfredsson L, Michélsen H, Vingård E, Kilbom Å

The following articles refer to this text: 2004;30(4):261-278;

2009;35(1):48-55

Key terms: epidemiology; exposure assessment; low back; misclassification; neck symptom; occupation; shoulder symptom

This article in PubMed: www.ncbi.nlm.nih.gov/pubmed/10569460

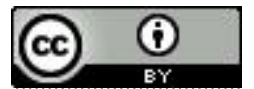




\title{
Retrospective versus original information on physical and psychosocial exposure at work
}

\author{
by Max Köster, BSc, ${ }^{1,2}$ Lars Alfredsson, PhD, ${ }^{2,3}$ Hans Michélsen,PhD, ${ }^{2}$ Eva Vingård, MD, ${ }^{1,2}$ Åsa Kilbom, \\ $M D^{1}$
}

\begin{abstract}
Köster M, Alfredsson L, Michélsen H, Vingård E, Kilbom A. Retrospective versus original information on physical and psychosocial exposure at work. Scand J Work Environ Health 1999;25(5):410-414.
\end{abstract}

\begin{abstract}
Objectives Retrospective exposure assessments are often performed in epidemiologic studies. The presence of an eventual misclassification, both nondifferential and differential, is debated but can rarely be investigated. The aim of this study was to compare self-reported information on the same physical and psychosocial work exposures with 25 years' difference.

Methods In 1969-1970 a survey of randomly chosen men and women in Stockholm county, concerning, among other things, work exposures, was undertaken. During 1993-1994, 280 subjects participated in a reexamination, regarding psychosocial and physical factors at work and musculoskeletal disorders. The questions were all formulated in the same way as in 1969-1970.

Results When self-reported information on work exposures, collected with a 25-year interval, was compared, acceptable, although not high, agreement was found for 3 out of 4 physical factors and for 4 out of 10 physical environmental factors. Questions measuring psychosocial load had somewhat lower agreement. Current exposure status influenced the memory of past exposures. Study subjects who reported low-back disorders at the reexamination tended to show a better agreement in their assessments of retrospective exposures than those without current symptoms. When relative risks from original and retrospective data were calculated, hardly any influence on the estimates due to that differential misclassification could be found. For persons with and without neck or shoulder symptoms no apparent differences in assessments were found.

Conclusions Retrospective assessments of exposures at the workplace showed misclassifications to a certain degree. However, the influence of the misclassifications on the risk estimates was limited.
\end{abstract}

Key terms epidemiology, exposure assessments, low back, misclassification, neck-shoulder, occupation.

In epidemiologic research continuous longitudinal data on exposure is highly desirable but very difficult to obtain. In follow-up studies a baseline exposure assessment is often available, and then the cohort is followed with regard to cases of disease. One limitation of this strategy is that changes in exposure status during follow-up lead to biased estimates of the risks. Case-referent studies usually make it easier in practice to follow exposures over time since all assessments can be collected on 1 occasion. However the value of the retrospective information depends on the reliability (ie, the nature and degree of misclassification introduced) $(1,2)$.

If this misclassification of exposure is nondifferential, estimates of the relative risk are usually biased towards the null (ie, the strength of the relationship is underestimated). An overestimation can also take place if the exposure has not been dichotomously categorized (3).

Given an observed relative risk differing from unity, the potential bias from differential misclassification is often considered a problem. Such a bias can occur if cases and noncases or referents recall their exposure differently in a case-referent study or in a cohort study where the exposure information has been collected retrospectively. Determining whether a differential misclassification has occurred is complicated and is, in most cases, impossible to investigate.

Surprisingly little is known of the quality of retrospective exposure information (4). Some studies on smoking, dietary habits, and alcohol consumption have

1 National Institute for Working Life, Solna, Sweden.

2 Department of Occupational Health, Karolinska Hospital, Stockholm, Sweden.

3 Institute of Environmental Medicine, Karolinska Institute, Stockholm, Sweden.

Reprint requests to: Mr Max Köster, Centre for Epidemiology, National Board of Health and Welfare, 10630 Stockholm, Sweden. [E-mail max.koster@sos.se] 
compared self-reported retrospective data to self-reported original information (5-9). Two such studies also addressed the question of differential misclassification (7, 8 ). In summary they showed that the current exposure for an individual colors the memory of distant exposures (ie, persons who have changed habits between the data collection times tend to over- or underestimate their previous exposure depending on the direction in which they have changed that exposure.

The aim of this study was to compare self-reported information on physical and psychosocial work exposures in 1969-1970, the data on which were collected by questionnaire at that time, with corresponding self-reported retrospective information on the same work exposures in $1969-1979$, the data for which were collected in 1993-1994 (ie, with a 25-year difference). Special interest was paid to the potential presence of differential misclassification for persons with and without current musculoskeletal disorders.

\section{Subjects and methods}

In 1969-1970 a survey, the REBUS study, of 2500 randomly chosen men and women between 19 and 65 years of age living in Stockholm County was undertaken. The purpose was to investigate the requirements for medical and social services and to measure discrepancies between actual needs and the measures taken so far to meet these needs (10).

During 1993-1994 REBUS subjects who were still below 59 years of age and living in Sweden were identified and asked to participate in a re-examination, regarding psychosocial and physical factors during work and leisure time and musculoskeletal disorders. Persons with a musculoskeletal diagnosis in the 1969-1970 survey were not included in the present study. Four hundred and eighty-four subjects ( 232 men and 252 women) participated in the re-examination.

Altogether 280 of those who were working at the time of the original REBUS survey were included in the present study (table 1). They were all asked about a set of work environmental factors concerning their work in 1969-1970 and their present work in 1993-1994. The questions were all formulated in the same way as in 1969-1970, except that the retrospective questions were in the past tense.

The questions, concerning physical load, psychosocial load, dirt, air quality, noise, and exposure to vibration at work, all with responses on a dichotomous scale, have been used in several questionnaires and surveys in Sweden.

The degree of agreement between answers about job exposures in 1969-1970 given in the questionnaire of
1969-1970 and those given in 1993-1994 was calculated by means of the kappa statistic, together with the 95\% confidence interval (11). Kappa measures the degree of agreement beyond the agreement expected by chance. Coefficients of 0.40 and higher are considered acceptable. Estimates of the specificity and sensitivity of the retrospective exposure information was calculated on the assumption that original information from 19691970 was true.

Seven of the questions concerned factors that are usually associated with musculoskeletal disorders (heavy lifting, physically demanding work, monotonous work, work under time-pressure, daily perspiring from physical exertion, and contact with dirt at work). For these questions the degree of agreement has been evaluated separately for subjects with and without reported musculoskeletal symptoms from the low-back and neck-shoulder regions at the reexamination in 1993-1994. These symptoms were measured by a questionnaire (12) and concerned symptoms during the last 12 months. The prevalence was $51 \%$ for symptoms from the low-back region, and $57 \%$ for the neck-shoulder region among the 280 persons studied. When the groups with and without symptoms were compared, ratios of sensitivity and specificity were calculated for each of the 7 questions using the Mantel Haenszel method after adjustment for age $(41-49$ years old and 50-58 years old) and gender.

In addition for each of the 7 questions, the relative risk adjusted for gender and age of having a musculoskeletal problem, calculated from the original data on exposure, was compared with the relative risk calculated with retrospective data on the same exposure.

\section{Results}

Three of the 4 questions on physical load had acceptable, although not high, kappa coefficients (table 2). The question on physical exhaustion had a low value, as did exposures of psychosocial nature.

For questions concerning physical load the specificities ranged from 0.8 to 0.9 , while the sensitivities where lower, 0.5 to 0.7 . The questions regarding mentally demanding work, work under time pressure, and mental exhaustion had somewhat lower values. The specificities and sensitivities for these questions ranged from 0.6 to 0.8 and from 0.5 to 0.7 , respectively.

Table 1. Distribution of the 280 subjects according to gender and age in 1993.

\begin{tabular}{lccc}
\hline & Age $41-49$ & Age $50-58$ & All \\
\cline { 2 - 4 } Men & 93 & 76 & 169 \\
Women & 75 & 36 & 111 \\
All & 168 & 112 & 280 \\
\hline
\end{tabular}


Table 2. Agreement between original and retrospective exposure information. Kappa coefficients with $95 \%$ confidence intervals (95\% Cl) together with exposure prevalences for 1969-1970. Sensitivity and specificity of the reported retrospective exposure information from 1993-1994 has been calculated using original responses as true values.

\begin{tabular}{|c|c|c|c|c|}
\hline & Kappa & $95 \% \mathrm{Cl}$ & $\begin{array}{c}\text { Exposure } \\
1969-1970 \\
(\%)\end{array}$ & $\begin{array}{l}\text { Sensitivity/ } \\
\text { specificity }\end{array}$ \\
\hline \multicolumn{5}{|l|}{ Physical load } \\
\hline Do you need to lift $40 / 60 \mathrm{~kg}$ at work? a & 0.56 & $0.45-0.67$ & 24 & $0.7 / 0.8$ \\
\hline Is your work physically demanding? & 0.41 & $0.29-0.53$ & 33 & $0.6 / 0.8$ \\
\hline Does sweating from exertion occur daily? & 0.41 & $0.28-0.54$ & 20 & $0.6 / 0.9$ \\
\hline Do you often feel physically exhausted? & 0.28 & $0.15-0.41$ & 19 & $0.5 / 0.8$ \\
\hline \multicolumn{5}{|l|}{ Psychosocial factors } \\
\hline Is the work mentally demanding? & 0.35 & $0.23-0.46$ & 43 & $0.5 / 0.8$ \\
\hline Do you work under time pressure? & 0.30 & $0.18-0.42$ & 66 & $0.7 / 0.6$ \\
\hline Is the work monotonous? & 0.24 & $0.10-0.39$ & 16 & $0.3 / 0.9$ \\
\hline Do you often feel mentally exhausted & & & & \\
\hline when you come home from work? & 0.24 & $0.11-0.37$ & 79 & $0.5 / 0.7$ \\
\hline \multicolumn{5}{|l|}{ Physical environment } \\
\hline Do you get dirty at work? & 0.50 & $0.39-0.61$ & 36 & $0.7 / 0.8$ \\
\hline Is it noisy where you work? & 0.35 & $0.24-0.47$ & 39 & $0.6 / 0.7$ \\
\hline Do you work indoors only? & 0.69 & $0.59-0.78$ & $70^{\circ}$ & $0.9 / 0.7$ \\
\hline Do you work in a normal room temperature? & 0.18 & $0.01-0.35$ & $80^{\circ}$ & $0.9 / 0.2$ \\
\hline Is it drafty where you work? & 0.26 & $0.13-0.40$ & 22 & $0.4 / 0.8$ \\
\hline Do you often feel cold where you work? & 0.33 & $0.18-0.47$ & 15 & $0.4 / 0.9$ \\
\hline Is it damp or wet at work? & 0.41 & $0.27-0.56$ & 15 & $0.6 / 0.9$ \\
\hline Are you exposed to heavy vibration? & 0.50 & $0.36-0.64$ & 11 & $0.9 / 0.8$ \\
\hline Are you exposed to gas, dust or smoke at work? & 0.42 & $0.30-0.53$ & 58 & $0.8 / 0.7$ \\
\hline Are you in contact with poisonous substances at work? & 0.50 & $0.37-0.62$ & 23 & $0.6 / 0.9$ \\
\hline
\end{tabular}

a Women were asked about $40 \mathrm{~kg}$ and men about $60 \mathrm{~kg}$.

b Work indoors and work in a normal temperature were considered conditions of exposure.

Table 3. Sensitivity and specificity of 7 questions for subjects with and without low-back symptoms. The age- and gender-adjusted ratio between sensitivity and specificity with $95 \%$ confidence intervals $(95 \% \mathrm{Cl}$ ) as a measure of difference between the groups.

\begin{tabular}{|c|c|c|c|c|c|c|c|c|}
\hline \multirow[t]{2}{*}{ Exposures measured } & \multicolumn{4}{|c|}{ Sensitivity } & \multicolumn{4}{|c|}{ Specificity } \\
\hline & Symptoms & No symptoms & Ratio & $95 \% \mathrm{Cl}$ & Symptoms & No symptoms & Ratio & $95 \% \mathrm{Cl}$ \\
\hline 1. Lifting $40 / 60 \mathrm{~kg}$ & 0.85 & 0.59 & 1.47 & $1.05-2.06$ & 0.85 & 0.84 & 1.00 & $0.89-1.13$ \\
\hline 2. Physically demanding & 0.70 & 0.46 & 1.48 & $1.02-2.16$ & 0.81 & 0.84 & 0.97 & $0.84-1.11$ \\
\hline 3. Perspiring from exertion & 0.53 & 0.57 & 1.01 & $0.60-1.68$ & 0.84 & 0.89 & 0.96 & $0.86-1.06$ \\
\hline 4. Work under time pressure & 0.69 & 0.72 & 1.01 & $0.83-1.22$ & 0.64 & 0.52 & 1.19 & $0.84-1.68$ \\
\hline 5. Monotonous work & 0.43 & 0.22 & 2.27 & $0.84-6.13$ & 0.89 & 0.89 & 1.00 & $0.91-1.09$ \\
\hline 6. Noisy & 0.64 & 0.58 & 1.08 & $0.79-1.47$ & 0.78 & 0.75 & 1.02 & $0.86-1.20$ \\
\hline 7. Heavy vibration & 0.94 & 0.80 & 1.22 & $0.96-1.57$ & 0.86 & 0.85 & 1.01 & $0.91-1.12$ \\
\hline
\end{tabular}

Table 4. Sensitivity and specificity of 7 questions for subjects with and without neck or shoulder symptoms. The age- and genderadjusted ratio between sensitivity and specificity with $95 \%$ confidence intervals $(95 \% \mathrm{Cl})$ as a measure of difference between the groups.

\begin{tabular}{|c|c|c|c|c|c|c|c|c|}
\hline \multirow[t]{2}{*}{ Exposures measured } & \multicolumn{4}{|c|}{ Sensitivity } & \multicolumn{4}{|c|}{ Specificity } \\
\hline & Symptoms & No symptoms & Ratio & $95 \% \mathrm{Cl}$ & Symptoms & No symptoms & Ratio & $95 \% \mathrm{Cl}$ \\
\hline 1. Lifting $40 / 60 \mathrm{~kg}$ & 0.77 & 0.67 & 1.28 & $0.93-1.76$ & 0.84 & 0.84 & 0.95 & $0.84-1.07$ \\
\hline 2. Physically demanding & 0.64 & 0.50 & 1.29 & $0.87-1.93$ & 0.80 & 0.87 & 0.90 & $0.78-1.03$ \\
\hline 3. Perspiring from exertion & 0.58 & 0.50 & 1.20 & $0.70-2.06$ & 0.91 & 0.79 & 1.07 & $0.96-1.20$ \\
\hline 4. Work under time pressure & 0.69 & 0.70 & 0.94 & $0.78-1.15$ & 0.56 & 0.63 & 0.82 & $0.57-1.17$ \\
\hline 5. Monotonous work & 0.34 & 0.33 & 0.79 & $0.26-2.40$ & 0.87 & 0.91 & 0.96 & $0.88-1.05$ \\
\hline 6. Noisy & 0.62 & 0.59 & 1.16 & $0.85-1.56$ & 0.77 & 0.74 & 0.97 & $0.81-1.16$ \\
\hline 7. Heavy vibration & 0.82 & 0.93 & 0.95 & $0.74-1.22$ & 0.87 & 0.83 & 1.01 & $0.91-1.13$ \\
\hline
\end{tabular}

The question on monotonous work showed a specificity of 0.9 but a rather poor sensitivity of 0.3 .

For the remaining questions, contact with dirt, work indoors, exposure to heavy vibration, and contact with poison, the answers on the 2 occasions were highly correlated. Their sensitivities and specificities were also high.

The sensitivities and specificities of the 7 questions 
Table 5. Relative risk, adjusted for age and gender, of low-back pain and neck or shoulder symptoms for different factors based on original and retrospective exposure data.

\begin{tabular}{|c|c|c|c|c|c|c|c|c|}
\hline \multirow[t]{3}{*}{ Exposure measured } & \multicolumn{4}{|c|}{ Low-back symptoms } & \multicolumn{4}{|c|}{ Neck or shoulder symptoms } \\
\hline & \multicolumn{2}{|c|}{ Original data } & \multicolumn{2}{|c|}{ Retrospective data } & \multicolumn{2}{|c|}{ Original data } & \multicolumn{2}{|c|}{ Retrospective data } \\
\hline & $\mathrm{RR}$ & $95 \% \mathrm{Cl}$ & $\mathrm{RR}$ & $95 \% \mathrm{Cl}$ & $R R$ & $95 \% \mathrm{Cl}$ & $\mathrm{RR}$ & $95 \% \mathrm{Cl}$ \\
\hline 1. Lifting 40/60 kg & 1.11 & $0.84-1.48$ & 1.18 & $0.91-1.54$ & 1.12 & $0.87-1.46$ & 1.22 & $0.96-1.56$ \\
\hline 2. Physically demanding & 1.03 & $0.80-1.32$ & 1.23 & $0.98-1.59$ & 1.12 & $0.90-1.39$ & 1.28 & $1.03-1.60$ \\
\hline 3. Perspiring from exertion & 1.23 & $0.92-1.64$ & 1.18 & $0.88-1.56$ & 1.16 & $0.91-1.50$ & 0.95 & $0.71-1.26$ \\
\hline 4. Work under time pressure & 0.91 & $0.72-1.16$ & 0.87 & $0.68-1.12$ & 0.95 & $0.76-1.18$ & 1.01 & $0.82-1.25$ \\
\hline 5. Monotonous work & 1.12 & $0.82-1.54$ & 1.16 & $0.84-1.58$ & 1.28 & $0.99-1.66$ & 1.18 & $0.92-1.51$ \\
\hline 6. Noisy & 1.00 & $0.78-1.27$ & 1.02 & $0.80-1.31$ & 1.01 & $0.82-1.24$ & 1.10 & $0.88-1.37$ \\
\hline 7. Heavy vibration & 1.04 & $0.71-1.53$ & 1.05 & $0.77-1.44$ & 1.07 & $0.75-1.55$ & 0.98 & $0.73-1.31$ \\
\hline
\end{tabular}

of special interest in the context of musculoskeletal disorders are presented separately for subjects with and without low-back symptoms (table 3 ), and also for neckshoulder symptoms (table 4).

The specificities for all the items, both for those with and without low-back and neck or shoulder symptoms, were high, except for "work under time pressure". The sensitivity for "monotonous work" had an extremely low value for persons both with and without symptoms. At the other extreme was "heavy vibration" with values between 0.80 to 0.94 . Differential misclassification was evident for heavy lifting and physically demanding work with regard to low-back disorders but not with regard to neck or shoulder disorders to the same degree. The effect on the relative risk estimates was, in general, very small when the original and retrospective information was compared (table 4). The biggest differences between the 2 relative risks were seen for physically demanding work tasks (overestimation) and daily perspiring from exertion (underestimation).

For those exposed in 1969-1970, table 5 presents a comparison of the quality of the exposure information for those who reported exposure at the time for REBUS 1993-1994 and those who did not. The subjects who changed their exposure class from exposed to unexposed from 1970 to 1993 seemed to underestimate their exposure to a high degree. Such underestimation occurred both for subjects with low-back symptoms and those without. In general, those who had no low-back symptoms in 1993 - 1994 and were unexposed in 1993-1994 underestimated their exposure the most, although the groups of subjects were small.

A separate analysis was made for the persons reporting exposure in 1969-1970 and also exposed in 19931994. The sensitivities for all persons, as well as for the 2 groups with and without current low-back symptoms, are shown in table 6 . The persons with high exposure also in the job held in 1993-1994 recalled their exposure in 1979-1980 better than those unexposed today. In general the highest sensitivities were found for those both exposed today and with current low-back symptoms.
Table 6. Sensitivity for different questions for the subjects originally exposed in 1969-1970 by reported exposure status in 1993-1994. The values are displayed for all persons combined, as well as for those with and without current low-back symptoms separately.

\begin{tabular}{|c|c|c|c|c|c|c|}
\hline \multirow[t]{2}{*}{$\begin{array}{l}\text { Exposure variables } \\
1969-1970\end{array}$} & \multicolumn{2}{|c|}{ All } & \multicolumn{2}{|c|}{$\begin{array}{l}\text { Low-back } \\
\text { symptoms }\end{array}$} & \multicolumn{2}{|c|}{$\begin{array}{l}\text { No low-back } \\
\text { symptoms }\end{array}$} \\
\hline & N & $\begin{array}{l}\text { Sensi- } \\
\text { tivity }\end{array}$ & $\mathrm{N}$ & $\begin{array}{l}\text { Sensi- } \\
\text { tivity }\end{array}$ & N & $\begin{array}{l}\text { Sensi- } \\
\text { tivity }\end{array}$ \\
\hline \multicolumn{7}{|l|}{ 1. Lifting $40 / 60 \mathrm{~kg}$} \\
\hline $\begin{array}{l}\text { Exposeda } \\
\text { Unexposeda }\end{array}$ & $\begin{array}{l}20 \\
16\end{array}$ & $\begin{array}{l}0.95 \\
0.53\end{array}$ & $\begin{array}{l}13 \\
11\end{array}$ & $\begin{array}{l}1.00 \\
0.69\end{array}$ & $\begin{array}{l}7 \\
5\end{array}$ & $\begin{array}{l}0.88 \\
0.36\end{array}$ \\
\hline \multicolumn{7}{|c|}{ 2. Physically demanding } \\
\hline $\begin{array}{l}\text { Exposeda } \\
\text { Unexposeda }\end{array}$ & $\begin{array}{l}18 \\
21\end{array}$ & $\begin{array}{l}0.67 \\
0.51\end{array}$ & $\begin{array}{l}14 \\
11\end{array}$ & $\begin{array}{l}0.74 \\
0.58\end{array}$ & $\begin{array}{r}4 \\
10\end{array}$ & $\begin{array}{l}0.50 \\
0.45\end{array}$ \\
\hline \multicolumn{7}{|c|}{ 3. Perspiring from exertion } \\
\hline $\begin{array}{l}\text { Exposeda }^{a} \\
\text { Unexposeda }\end{array}$ & $\begin{array}{r}12 \\
7\end{array}$ & $\begin{array}{l}0.75 \\
0.30\end{array}$ & $\begin{array}{l}7 \\
4\end{array}$ & $\begin{array}{l}0.64 \\
0.29\end{array}$ & $\begin{array}{l}5 \\
3\end{array}$ & $\begin{array}{l}1.00 \\
0.33\end{array}$ \\
\hline \multicolumn{7}{|c|}{ 4. Work under time pressure } \\
\hline $\begin{array}{l}\text { Exposeda } \\
\text { Unexposed }\end{array}$ & $\begin{array}{l}88 \\
18\end{array}$ & $\begin{array}{l}0.79 \\
0.42\end{array}$ & $\begin{array}{l}39 \\
12\end{array}$ & $\begin{array}{l}0.72 \\
0.50\end{array}$ & $\begin{array}{r}49 \\
6\end{array}$ & $\begin{array}{l}0.84 \\
0.32\end{array}$ \\
\hline \multicolumn{7}{|l|}{ 5. Monotonous work } \\
\hline $\begin{array}{l}\text { Exposeda } \\
\text { Unexposeda }\end{array}$ & $\begin{array}{l}4 \\
9\end{array}$ & $\begin{array}{l}0.57 \\
0.29\end{array}$ & $\frac{2}{7}$ & $\begin{array}{l}0.50 \\
0.39\end{array}$ & $\begin{array}{l}2 \\
2\end{array}$ & $\begin{array}{l}0.67 \\
0.15\end{array}$ \\
\hline \multicolumn{7}{|l|}{ 6. Noisy } \\
\hline $\begin{array}{l}\text { Exposeda } \\
\text { Unexposeda }\end{array}$ & $\begin{array}{l}27 \\
26\end{array}$ & $\begin{array}{l}0.84 \\
0.43\end{array}$ & $\begin{array}{l}15 \\
15\end{array}$ & $\begin{array}{l}0.83 \\
0.52\end{array}$ & $\begin{array}{l}12 \\
11\end{array}$ & $\begin{array}{l}0.86 \\
0.35\end{array}$ \\
\hline \multicolumn{7}{|l|}{ 7. Heavy vibration } \\
\hline $\begin{array}{l}\text { Exposed }^{a} \\
\text { Unexposed }\end{array}$ & $\begin{array}{r}12 \\
9\end{array}$ & $\begin{array}{l}1.00 \\
0.75\end{array}$ & $\begin{array}{l}6 \\
6\end{array}$ & $\begin{array}{l}1.00 \\
0.86\end{array}$ & $\begin{array}{l}6 \\
3\end{array}$ & $\begin{array}{l}1.00 \\
0.60\end{array}$ \\
\hline
\end{tabular}

${ }^{a}$ Refers to exposure in 1993-1994.

\section{Discussion}

The questions in the original REBUS study on occupational exposures were rough, not very sophisticated, and only on a dichotomous level, as the exposures were not the main target of study.

Nevertheless, retrospective exposure information concerning physical load after 25 years showed acceptable agreement with the original data for 3 factors out of 4 . So did also 4 out of 10 physical environmental factors (contact with dirt, indoor work, contact with poison, and 
heavy vibration). Questions measuring psychosocial load had lower agreements.

Study subjects who reported low-back or neck and shoulder disorders at the reexamination had better agreement in their assessments of retrospective exposures than did those without current symptoms. When the relative risks were calculated from the original and retrospective data, hardly any influence on the estimates due to the differential misclassification could be found. However $51 \%$ of the cohort reported low-back pain, and $57 \%$ had neck or shoulder pain. With such a high prevalence the association with risk exposures is not likely to be strong.

We also found that current exposure status influences the memory of past exposures. This finding agrees with the results of earlier studies on other exposures. In a Swedish investigation on cigarette smoking 10356 persons who, on a postal questionnaire, reported that they smoked in 1963, were asked again in 1969, using identical questions, about their current smoking habits and those in 1963 (7). When compared with the original information on smoking, the retrospective information showed a strong tendency to overestimate the previous cigarette consumption of the subjects who had increased their cigarette smoking and to underestimate the previous consumption of those who had decreased their cigarette smoking. Subjects with unchanged habits showed a high level of agreement between the original and retrospective information. The same subjects were also followed to 1979 for the occurrence of ischemic heart disease and lung cancer. The relative risks of death based on original and retrospective information on smoking were then calculated. They did not differ in a substantial way when different sources of exposure data were used, and therefore only minor influence from differential misclassification was indicated.

Other studies in which original exposure information has been compared with retrospective information concern dietary habits and bowel cancer $(5,9)$. In these investigations a similar pattern as for smoking was found. Those who had changed habits in the period between the data collections tended to over- or underestimate their previous exposure, depending on the direction in which they had changed their habits.

The same observation has been made concerning selfreported alcohol consumption and physical activity (4).

In the present study we found a tendency towards differential misclassification for some exposures when comparing respondents with and without low-back symptoms. Persons with current symptoms tended to remember past physical loads from heavy lifting and physically demanding tasks to a higher degree than those without current symptoms. Concerning heavy lifting, burdens of
40 to 60 kilograms were asked for. Such heavy lifting hardly exists any longer, and therefore it is probably harder to remember. For physically demanding tasks methods involving something other than a dichotomous response design is preferred nowadays (13). Reporting of monotonous work tasks also showed differential misclassification. However, few were exposed, and the sensitivity was low for both persons with and without symptoms. The remaining types of exposures did not show any serious tendency toward differential misclassification.

However, no significant differential misclassification was observed for exposure reporting for persons with and without neck or shoulder symptoms. We have no good explanation why persons with different diagnoses differ in their ability to remember exposures.

\section{References}

1. Kopec JA, Esdaile JM. Bias in case-control studies: a review. J Epidemiol Community Health 1990;44:179-86.

2. Greenland S, Robins JM. Confounding and misclassification Am J Epidemiol 1985;122:495—506.

3. Flegal KM, Keyl PM, Nieto FJ. Differential misclassification arising from nondifferential errors in exposure measurements. Am J Epidemiol 1991;134:1233-44.

4. Friedereich $\mathrm{C}$ M. Improving long-term recall in epidemiological studies [editorial]. Epidemiology 1994;5:1-4.

5. Byers T, Marshall J, Antony E, Fiedler R, Zielenzny M. The reliability of dietary history from the distant past. Am J Epidemiol 1987;125:999-1011.

6. Czarnecki DM, Russel M, Cooper ML, Salter D. Five-year reliability of self-reported alcohol consumption. J Stud Alcohol 1990;51:68-76.

7. Persson P-G, Norell S. Retrospective versus original information on cigarette smoking, Am J Epidemiol 1989;130:70512.

8. Persson P-G, Norell S. Retrospective versus original information on diet: implications for epidemiological studies. Int J Epidemiol 1990;19:343-8.

9. Hammar N, Norell S. Retrospective versus original information on diet among cases of colorectal cancer and controls. Int J Epidemiol 1991;20:621-7.

10. Bygren LO. Met and unmet needs for medical and social services. Scand J Soc Med 1974, suppl 8.

11. Fleiss JL. The measurement of interrater agreement. In: Statistical methods for rates and proportions. New York (NY): John Wiley \& sons Inc, 1981:212-25.

12. Kuorinka I, Jonsson B, Kilbom $\AA$, Vinterberg H, BieringSørensen F, Andersson G, et al. Standardized Nordic questionnaires for the analysis of musculoskeletal symptoms. Appl Ergon 1987;18:233-7.

13. Borg G. Perceived exertion as an indicator of somatic stress. Scand J Rehabil Med 1970;2:92-8.

Received for publication: 16 October 1998 